\title{
A Regional model study of synoptic features over West Africa
}

\section{Leonard M. Druyan, Matthew Fulakeza}

Center for Climate Systems Research, Columbia University at the NASA/Goddard Institute for Space Studies, 2880 Broadway, New York, NY 10025

\section{Patrick Lonergan}

Science Systems and Applications, Inc. ai the NASA/Goddard Institute for Space Studies, 2880 Broadway. New York, NY 10025

and Mah aman Saloum

Direction de La Météorologi. Nationale, BP 218 Niamey, Niger

November 2000

$$
\begin{gathered}
\text { Monthly weather Review } \\
\text { in press }
\end{gathered}
$$




\begin{abstract}
Synoptic weather features over West Africa were studied in simulations by the regional simulation model (RM) at the NASA/Goddard Institute for Space Studies. These pioneering simulations represent the beginning of an effort to adapt regional models for weather and climate prediction over West Africa. The RM uses a cartesian grid with $50 \mathrm{~km}$ horizontal resolution and fifteen vertical levels. An ensemble of four simulations was forced with lateral boundary conditions from ECMWF global analyses for the period 8-22 August 1988. The simulated mid-tropospheric circulation includes the skillful development and movement of several African wave disturbances. Wavelet analysis of mid-tropospheric winds detected a dominant periodicity of about 4 days and a secondary periodicity (f 5-8 days. Spatial distributions of RM precipitation and precipitation time series were validated against daily rain gauge measurements and ISCCP satellite infrared cloud imagery. The time-space distribution of simulated precipitation was made more realistic by combining the ECMWF initial conditions with a 24-hr spin-up of the moisture field and also by damping high frequency gravity waves by dynamic initialization. Model precipitation "forecasts" over the Central Sahel were correlated with observations for about three days, but reinitializing with observed data on day 5 resulted in a dramatic improvement in the precipitation validation over the remaining 9 days. Results imply that information via the lateral boundary conditions is not always sufficient to minimize departures between simulated and actual precipitation patterns for more than several days. In addition, there was some evidence that the new initialization may increase the simulations' sensitivity to the quality of lateral boundary conditions.
\end{abstract}




\section{Introduction}

The rainy season in West Africa is June-September and African wave disturbances (AWD) and squall lines are important precipitation triggers (Peters et al., 1989). Typical AWD wave lengths are about $2500 \mathrm{~km}$ (Burpee, 1972), but convergence zones, vertical motion extremes and squall lines are often confined to one wave sector (Reed et al., 1977). According to Kamara (1986), considerable precipitation also occurs within moist monsoon flows not associated with AWD. Recurring Sahel droughts with negative socioeconomic impacts reinforce the importance of improving our understanding of the interannual variability of this region's climate. In addition, improved daily weather forecasts offer obvious benefits to many sectors of the society.

The study of the local weather and climate of West Africa should appropriately relate to the analysis and simulation of AWD and their associated mesoscale structures. For diagnostic or predictive studies, the scale of perceived spatial details of these weather making systems depends on the horizontal resolution of the meteorological analysis/simulation model grid lattice. Druyan et al. (1997) showed that spatial features related to divergence and vertical motion near AWD became better defined when ECMWF analysis resolution was increased from $4^{\circ} \times 5^{\circ}$ to $2^{\circ} \times 2.5^{\circ}$.

Reed et al. (1988) investigated the structure of AWD in the ECMWF operational analysis and forecast system's gridded data sets for AugustSeptember 1985. Physical parameterizations in the ECMWF model used in the 
study had previously been revised and resolution had been increased to T106 (equivalent to $1.1^{\circ}$ horizontal resolution). Patterns of $700 \mathrm{mb}$ vorticity variance in the 3-5 day frequency band from these data identified AWD trajectories across West Africa along $12^{\circ} \mathrm{N}$ and $22^{\circ} \mathrm{N}$, but associated precipitation patterns were not studied. Semazzi et al. (1993) simulated the climate of West Africa for the summers of 1950 and 1984 with an 80- km horizontal resolution nested regional model. While their study examined mean precipitation fields, it did not consider the role of AWD. Jenkins (1997) discussed similar results at $110-\mathrm{km}$ resolucion for the contrasting 1988 and 1990 summers. Xue and Shukla (1993) use 1 a high resolution global model to demonstrate the negative impact of deforıstation on AWD related precipitation over West Africa during one season.

Druyan et al. (1996) related the precipitation recorded at Niamey (Niger) to the AWD of 10-11 August 1988, and Druyan et al. (1997) investigated its structure at $2 \times 2.5^{\circ}$ resolution. Neither study referred to the concurrent spatial distribution of precipitation over West Africa.

Sun et al. (1999a,b) described climate simulations made over eastern Africa at $60-\mathrm{km}$ resolution using the RegCM2 model of NCAR. They found it prudent to customize the model by tuning it to the observed October climate (Sun et al., 1999a) before they applied it to the simulation of interannual variability. Sun et al. (1999b) discussed how ENSO and synoptic features of the large-scale circulation are related to simulated precipitation anomalies, but they did not discuss how the model's high horizontal resolution may have improved the analysis of near-surface circulation and temperature compared to the coarser gridded ECMWF data that was driving the model. 
We have previously documented the performance of the NASA/Goddard Institute for Space Studies (GISS ) regional model (RM) during one 7-day period during August 1988. The RM exploits the considerably higher, 50-km resolution of a limited area atmospheric model in order to better analyze the spatial structure of meteorological fields associated with synoptic features over West Africa. The model domain, $20^{\circ} \mathrm{S}-35^{\circ} \mathrm{N}, 35^{\circ} \mathrm{W}-35^{\circ} \mathrm{E}$, includes the region of AWD formation in the eastern Sahel, the region of cross-equatorial flow in the Gulf of Guinea, the entire Sahara and Atlantic coastal waters. Druyan et al. (2000) (hereafter DFT) showed reasonably skillful RM circulation forecasts at mid-troposphere, but poor time-space distribution of simulated precipitation. A common evolution in those 16 simulations was excessive rainfall during the first two days, followed by almost no precipitation afterwards. Subsequent testing found that the deficiency could be overcome by modifying the initial moisture field supplied from ECMWF analyses as discussed in section 3 .

The current study describes new simulations of West African circulation and precipitation by the GISS RM which use an initialization procedure to improve results. Initial conditions, taken from ECMWF gridded global analyses, are for 12 UTC on 8 August 1988 and the simulations continue to the end of 22 August 1988. An ensemble of four RM atmospheric simulations over West Africa are considered along with five additional simulations designed to evaluate the time rate of forecast deterioration and the relative importance of lateral boundary conditions. The uniqueness of these efforts is the application of a relatively high resolution regional model to problems of weather prediction in this area. While this investigation focuses on model 
performance for selected case studies of the evolution of daily circulation and precipitation over West Africa, future work will consider seasonal climate means and multi-year validation statistics. In all, ten simulations covering all or part of a two-week period in August 1988 are considered here.

\section{Regional Model}

The regional model (RM) at GISS was derived from a version developed at Florida State University (FSU). The RM has the same basic structure as the FSU global spectral model (Ross, 1991), except it uses a Cartesian ;rid with 50$\mathrm{km}$ spacing for dynamics and incorporates special treatment of sil moisture especially developed by Fulakeza (1998) for studies over Africa. Early versions were used by Kumar (1989) and Krishnamurti et al. (1990), the latter in a study demonstrating the positive impact of horizontal resolution on tropical predictions. The current version of the RM was described by DFT. The RM solves the primitive equations on 15 sigma surfaces using a semi-lagrangian advection scheme and semi-implicit time differencing. The treatment of long and short wave radiation transfer includes diurnal and seasonal variations, absorption by greenhouse gases and interactive clouds. Terrain topography is specified at $50 \mathrm{~km}$ resolution, consistent with the horizontal computing grid.

Deep convection is parameterized by the Kuo (1974) scheme, but it has been modified according to Krishnamurti et al. (1983, 1990). According to the original formulation, moistening and heating by the convective cloud are proportional to the humidity and temperature differences between the cloud and its environment. The proportion of the available heat and moisture 
supply that is assumed to be added to the column by cumulus convection must be assigned. To improve the match between simulated and observed rainfall, Krishnamuti et al. $(1983,1990)$ introduced mesoscale moisture convergence and moistening parameters. The mesoscale convergence is regarded as non-measurable and subgrid-scale.

In the modified scheme, the paramet?rization determines the moisture convergence and moistening parameters from knowledge of large scale variables. Krishnamurti et al. $(1983,1990)$ showed that the large scale vertically integrated vertical velocity and lower troposphere $(700 \mathrm{mb})$ relative vorticity can serve as successful proxies for the mesoscale moisture convergence and moistening parameters in the modified Kuo scheme. In the RM, the parameterization of cumulus convection follows this modified Kuo scheme. Deep cumulus convection parameterization is invoked when the atmosphere is conditionally unstable, vertical motion is upward, and a net supply of moisture convergence is available. To improve computing efficiency, the cloud base is taken to be at the lowest model level at which the relative humidity is greater than 0.8 while satisfying the above conditions (instead of determing the cloud base through a lifting condensation procedure). The thermodynamic structure within the cloud is obtained by constructing a moist adiabat from the cloud base. It is assumed that the moist static energy is conserved along this moist adiabat. The cloud top is defined as the level at which the cloud temperature is less than the temperature of the environment.

The basis of the present soil moisture parameterization was developed by Dastoor and Krishnamurti (1991) and improved by Bounoua (1992) and more 
recently by Fulakeza (1998). Soil moisture availability (SMA) is defined as the ratio of soil moisture at the surface to a maximum saturation value (field capacity). Second order regression equations for SMA were developed as functions of observed 5-day rainfall, albedo, surface temperature, normalized difference vegetation index (NDVI) and terrain relief, in order to account for the response of both the soil morphology and the climate forcing. The computation of preliminary SMA for the regression analysis was based on estimates of evaporation (latent heat flux) derived from moisture continuity considerations and computation of the surface radiative energy balance (see Dastoor and Krishnamurti, 1991). The derived regression equations (one for each of three soil types) are used by the RM to predict SMA during model simulations. NDVI is updated bi-weekly from satellite radiometric observations while land surface albedo evolves during the simulation according to variations in SMA, following Deardoff (1978). Accordingly, SMA is computed interactively as a function of model rainfall, albedo and surface temperature, as well as observed NDVI. Fulakeza (1998) showed that RMpredicted soil moisture and albedo have an impact on simulated rainfall over southern Africa through the modification of sensible and latent heat fluxes. The current study does not attempt to evaluate the impact of the SMA scheme on the simulations. Accordingly, it does not address the potentially important influence that SMA variability may have on the daily circulation or on precipitation rates over West Africa.

Prescribed lateral boundary conditions (LBC) are merged with the predicted RM evolution by weighting them with progressively decreasing weights inward within a buffer zone that completely surrounds the domain of interest. Accordingly, model computed fields along the lateral boundaries are 
smoothed to prevent high gradients between the driving analysis (outside) and model-computed variables within the domain. Optimal treatment of this approach avoids over-damping of incoming waves, but care must also be taken not to create reflections by too sharp a transition. The buffer zone consists of $n$ grid elements and the relative weights (wt) of the LBC vary according to the formulation,

$$
w t=k^{\star} \exp \left(-p^{\star} r\right)
$$

where $k$ and $p$ are coefficients that determine the relative influence of the LBC and $r$ is the row number from 1 to $n$. For the present simulations, the best results were obtained by using a buffer zone consisting of six grid elements $(n=6), k=2.2$ and $p=0.8$.

\section{Initialization and experiments}

A more realistic time-space distribution of precipitation, as compared to the results of DFT, is consistently obtained by modifying the initial moisture and circulation fields to improve their compatibility with the RM. After testing several approaches, we settled on a procedure for pre-processing ECMWF three-dimensional moisture distributions which gives encouraging results.

The humidity initialization procedure uses $24-\mathrm{hr}$ "predicted" relative humidities valid at $t_{0}$ (the beginning of the model simulation). The prediction is made in a pre-processing simulation that begins with ECMWF data at $t_{0}-24 \mathrm{~h}$. The resulting "spin-up" values of relative humidity are then combined with ECMWF temperatures at $t_{0}$ to compute the initial specific humidity $\left[\mathrm{Q}\left(\mathrm{t}_{0}\right)\right]$ at all levels. For the experiments described here, the pre- 
processing simulation began with ECMWF data at 12 UTC, 7 August 1988.

Relative humidity values "predicted" after $24 \mathrm{hr}$ (at $\mathrm{t}_{0}$ ) by this spin-up simulation, together with ECMWF temperatures for 12 UTC 8 August, then formed the basis for recomputing $Q\left(t_{0}\right)$. The resulting $Q\left(t_{0}\right)$ replaced $Q$ in the ECMWF data set for 12 UTC 8 August.

Overall results are additionally improved by "dynamic initialization", a procedure that eliminates high frequency gravity waves from the circulation fields given by ECMWF data sets. This step somewhat modifies surface pressures, geopotential heights and temperatures, but retains the same specific moisture distribution that is computed during the spin-úp cycle.

We employed the "dynamic initialization" described in detail by Krishnamurti et al. (1990), and based on the dynamic normal-mode initialization proposed by Sugi (1986). This method utilizes a forwardbackward iteration of the linear terms around the first time step while keeping the nonlinear forcings fixed. After every 100 linear iterations the non-linear terms are updated and the entire cycle is repeated. Efficient application of the procedure damps high frequency gravity waves faster than meteorologically significant lower frequency waves. Based on this criteria, the time integration scheme for the forward-backward iterations that was chosen by Krishnamurti et al. (1990), and used with the predecessor of the GISS RM, was a Eulerian scheme previously suggested by Okamura (see Haltiner and Williams, 1980). 
Model surface boundary conditions also include observed normalized difference vegetation index (NDVI) over land and observed sea-surface temperatures over ocean grid elements.

Giorgi and Mearns (1999) recommend that an RM first be evaluated using observational analyses for LBC. ECMWF analyses over sparse data regions such as West Africa provide somewhat less than "perfect LBC", but they are anchored to the observed meteorology. In the experiments described below, ECMWF data from gridded analyses convey information to the regional model in order to represent the influence of large scale circulation and global forcings. A thorough evaluation of RM skill based on observed LBC contributes to the interpretation of future downscaled GCM results.

The simulations described below were forced with $L B C$ that were time and space interpolated from ECMWF analyses every $12 \mathrm{hr}$. Random perturbations of $-1.5 \mathrm{mb}<\Delta \mathrm{P}<+1.5 \mathrm{mb}$ were applied to the initial surface pressure field in order to create four arbitrarily different sets of initial conditions. The ensuing four simulations were combined to form an ensemble average, referred to below as ENS. However, the study also includes several experiments that were based on single simulations.

\section{Precipitation validation}

a. Spatial distributions of ENS daily precipitation

August 9: Fig. 1a shows the streamflow pattern at $700 \mathrm{mb}$ from ECMWF $2.5 \times 2.5^{\circ}$ resclution analyses (hereafter EC) based on zonal and meridional 
wind components averaged for 00 and 12 UTC on 9 August 1988. The most prominent AWD trough over West Africa is in the vicinity of Lake Chad near $12^{\circ} \mathrm{E}$ (hereafter AWD1). An additional wave (AWD2) is analyzed near $3^{\circ} \mathrm{W}$ and a sharp trough appears along $10^{\circ} \mathrm{N}$ (hereafter the Gulf Coast Trough, GCT). The simulated circulation (Fig. 1b), based on zonal and meridional wind components averaged over eight synoptic times at three-hour intervals, 00-21 UTC, represents AWD1, AWD2 and the GCT quite well.

One of the problems encountered in the original set of simulations (DFT) was excessive rainfall during the first day. The initialization procedure succeeded in reducing rainfall amounts on Day 1 of the simulation (Fig. 1b) and in confining the more realistic precipitation maximum (about $10 \mathrm{~mm}$ ) to a smaller area which corresponds quite well to the observed distribution and to satellite imagery (Figs. 1c, 1d).

Aug. 10: Inspection of the EC $700 \mathrm{mb}$ streamflow analysis for 10 August 1988 (Fig. 1e) reveals only a small westward advance of the northern end of the AWD1 trough during the last $24 \mathrm{hr}$. In addition, a well formed AWD2 remains near $3^{\circ} \mathrm{W}$ and the breakdown of the GCT is noted. NCEP reanalyses confirm the longitude of AWD1 along $12^{\circ} \mathrm{E}$ on 10 August (not shown), but with a less pronounced westward tilt. In addition, NCEP reanalyses show a much shallower AWD2 at $5^{\circ} \mathrm{W}$. AWD2 is still evident in the model's circulation field (Fig. 1f) which also features a realistic tilt for AWD1.

The modeled precipitation areas (Fig. 1f) are situated close to and downstream from the AWD1 trough. The corresponding satellite image (Fig. $1 \mathrm{~g}$ ) shows a shield of bright clouds along about $6^{\circ} \mathrm{E}$, some $4^{\circ}$ ahead of the trough. Station reports (Fig. $1 \mathrm{~h}$ ) indicate precipitation over a $12^{\circ} \mathrm{swath}$ westward from the trough line with heaviest amounts between $0^{\circ}-5^{\circ} \mathrm{E}$. 
Overall, the spatial distribution and the amounts of simulated precipitation are quite realistic.

Aug. 11: The EC $700 \mathrm{mb}$ circulation (Fig. 1i) has reorganized into a large amplitude wave which dominates much of West Africa. There is evidence (not shown) that AWD1 and AWD2 merged before noon on the 11th. We continue to refer to this system as AWD1, which is linked to a closed cyclonic vortex over southern Nigeria on 11 August. The EC analyses indicate that the AWD1 trough advanced some $5^{\circ}$ longitude between 00 UTC $\left(7.5^{\circ} \mathrm{E}\right)$ and 12 UTC $\left(2.5^{\circ} \mathrm{E}\right)$ on 11 August, and NC.EP reanalyses indicate a similarly timed reorganization of AWD1. The moceled circulation correctly depicts the broader AWD1 trough with a realistic tilt.

The center of the modeled precifitation area (Fig. 1j) has moved westward of its previous position and it is nct far from where the satellite image (Fig. 1k) positions a convective complex and where station observations (Fig. 11) validate the more than $20 \mathrm{~mm}$ in simulated rainfall. Simulated and observed precipitation fields overlap, but the maxima are displaced relative to one another by several degrees. The broadest precipitation area remains downstream of the AWD1 trough, although both simulated and observed fields indicate a small area of heavy rainfall along $10^{\circ} \mathrm{E}$ where the broad trough maintains some cyclonic vorticity.

Aug. 12: The simulated circulation pattern (Fig. 1n) resembles the EC analysis (Fig. 1m); AWD1 has moved to the vicinity of $2^{\circ} \mathrm{E}$ and is associated with a cyclonic vortex at $0^{\circ}$. A much reduced area of rainfall at $10^{\circ} \mathrm{W}$ continues the model's pattern of precipitation downstream of the AWD1 trough, but it corresponds to only shallow clouds (Fig. 10) and no measured precipitation (Fig. 1p), although some rain is reported further downstream near the edge of bright clouds alor.g the Atlantic ITCZ. The single observation 
of $33 \mathrm{~mm}$ at Fada $\mathrm{N}^{\prime}$ Gourma $\left(12^{\circ} \mathrm{N}, 0^{\circ}\right.$, Burkina Faso) is suspiciously high in an area where no clouds are evident. On the other hand, the observation of 33 $\mathrm{mm}$ at Tessalit $\left(20^{\circ} \mathrm{N}, 1^{\circ} \mathrm{E}, \mathrm{Mali}\right)$ (not simulated) does correspond to a bright cloud cluster. Satellite and station data agree that the broadest area of convective activity occurs between $3^{\circ}-15^{\circ} \mathrm{E}$, within southeasterly circulation. The model shows only an isolated area at $11^{\circ} \mathrm{E}$ (Fig. In). This fourth day of the sequence evidences a marked deterioration between simulated and observed precipitation distributions.

Aug. 13: The circulation simulation correctly generates a new cyclonic center south of Lake Chad (Fig. 1r compared to Fig. 1q) and includes other realistic features, such as AWD1 reaching $8^{\circ} \mathrm{W}$. Widespread precipitation (Fig. 1t), slightly underestinated by the simulation (Fig. 1r), is associated with the northeast pointing trough near $5^{\circ} \mathrm{W}$ and also with convergence downstream from the new cyclonic center near $4^{\circ} \mathrm{E}$. Satellite imagery (Fig. 1s) shows a northwest-southeast squall line approximately corresponding to the rather heavy rates of modeled precipitation near $3-5^{\circ} \mathrm{E}$. Simulated precipitation amounts between $0^{\circ}-5^{\circ} \mathrm{E}$ reach about $44 \mathrm{~mm}$ (Fig. 1r), and correspond to observations ranging between 10-50 mm (Fig. 1t). However, the model fails to generate any precipitation west of $6^{\circ} \mathrm{W}$ where a number of stations report light rainfalls.

Aug. 14: EC (Fig. 1u) and NCEP analyses agree on the appearance of a wave in the northeasterlies at about $4^{\circ} \mathrm{E}$ on 14 August (hereafter AWD3), and this wave appears in the Day 6 model prediction (Fig. 1v). In addition, EC and NCEP show the reorganization of a northwest-southeast oriented GCT (AWD4) along $12^{\circ} \mathrm{N}$ and the simulation remarkably follows the same sequence. In addition, a new wave forming near Lake Chad (AWD5) on 14 August is also in licated by the modeled circulation. The northwest to 
southeast line of convective rainfall has intensified (Fig. 1x) contributing to accumulations in excess of $20 \mathrm{~mm}$ at many stations. The corresponding satellite image (Fig. 1w) shows that by 1500 UTC the convective complex is closer to the Atlantic coast than the 24-hr precipitation observations would indicate. The simulation greatly underestimates the spatial extent of this convective complex whose dynamic trigger is unclear from the analyzed or simulated circulation. In effect, the model reproduces only the southeastern end $\left(5^{\circ} \mathrm{W}\right)$, indicating reasonable rates in excess of $20 \mathrm{~mm}$. There is also evidence of isolated pockets of precipitation between $0^{\circ}-10^{\circ} \mathrm{E}$ where the model is showing no rainfall (Fig. 1v), and at $12^{\circ} \mathrm{E}$ which was simulated with a small southward displacement.

Aug. 15: The positions and configurations of the troughs appearing in the corresponding EC analysis (Fig. 1y) are all well represented in the circulation simulation shown in Fig. 1z, except that AWD3 has perhaps been damped too much.

Station data and satellite imagery (Figs. $1 z^{\prime}, z^{\prime \prime}$ ) refer to a large convective complex spanning about $10^{\circ}$ longitude and centered near $0^{\circ}$. One possible trigger is the GCT, but we also note that AWD5 is some $10^{\circ}$ upstream from this activity. The model has indeed suggested a limited area of moderate rainfall at this location (Fig. 1z). While the simulated precipitation rates of up to $35 \mathrm{~mm}$ are reasonable, the area covered by the rainfall is considerably underestimated. In addition, rather bright satellite cloud images corresponding to the off-shore ITCZ are also not matched by the model. Modeled rainfall along the AWD5 trough corresponds to several observations of very light accumulations.

We compared the $700 \mathrm{mb}$ circulation of these experiments with the results of DFT and found that the improvements in the time-space distribution of 
precipitation had a slight positive impact on the simulated circulation. For example, the formation of a northeast-southwest oriented trough over the southwest coastal area (Ivory Coast) on 13 August was handled better by these simulations. Also, on 15 August, the circulation over most of the domain is correctly more zonal than in the results of DFT and the newly developed AWD near Lake Chad better resembles the EC validation than in DFT. We postulate that the more realistic distribution of latent heat sources improved the simulation of horizontal temperature gradients, hence circulation.

\section{b. Precipitation time trends}

We validated the time trend of model.d ENS daily precipitation against station data over three areas. The first al ea average, comprised of only four grid points, was compared to co-located observations from three stations (Fig. 2, top); the second area average of 12 grid points was compared to six stations (Fig. 2, middle), and the third area of 162 grid points was compared to 18-19 stations (Fig. 2, bottom). The results show that the correspondence between modeled precipitation and observations is reasonable at all three spatial scales for the first two days. Increasing the size of the target area from four to 12 grid points improves the match on Day 3. Increasing the target area to 162 grid points improves the match also for Days 4-5. The discrepancy on 15 August is because the observed maximum was not simulated over a wide enough area. The results reflect model limitations in locating the exact position of rainfall maxima on a particular day. Since increasing the target area forgives spatial displacement errors, the correspondence improves for the larger areas. Beyond the favorable results for the initial days, RM precipitation time series for these areas are not correlated with observations. This implies that information contained in the initial con ditions was important for simulating 
rainfall. Although updated LBC convey something of the actual meteorological evolution to the region during the entire simulation, these data are apparently insufficient to force accurate evolution of the precipitation field. We tested whether reinitializing with EC data improves the modeled precipitation field. A single new run was begun from the EC data set of 12 UTC on 13 August 1988; moisture and dynamic initialization were applied, as before. The resulting improvement in precipitation rates over the three validation areas can be seen in Fig. 2. In each case precipitation rates on both the first and second full days (14-15 August) were much higher than for ENS. Moreover, in this reinitialized simulation, the maxima of 14-15 August were correctly followed first by decreases and then by a small increase on 21 August, closely paralleling the observational trend. The skill of this precipitation simulation perseveres some 8-9 days, considerably longer than for ENS. Additional testing is needed to determine whether the duration of skillful precipitation simulations is generally so variable. We suspect that such variability may be related to the quality of the initial state data and/or the complexity of the evolving meteorology.

\section{c. Weekly mean precipitation distributions}

The spatial distribution of mean modeled ENS precipitation rates for 9-15 August (Fig. 3a) shows a swath over West Africa that is nearly symmetric about $12^{\circ} \mathrm{N}$, with several maxima reaching between 6-15 mm day ${ }^{-1}$. According to station observations (Fig. $3 \mathrm{~b}$ ), the latitude interval between $10-15^{\circ} \mathrm{N}$ during the period 9-15 August 1988 experienced total accumulations mostly between 5-15 mm day ${ }^{-1}$. Modeled amounts were generally lower than the observed values, but the model correctly simulated the broadest swath of precipitation 
east of $10^{\circ} \mathrm{W}$. Heavy rainfall observed along the Atlantic coast was not simulated. The time series for the Central Sahel (Fig. 2) shows that much of the model's rainfall deficit occurred on 14-15 August. For 15 August the model has managed only a small fraction of the observed rainfall. Fig. 3d shows that during the second week, precipitation accumulations exceeding $10 \mathrm{~mm}$ are confined to the west of $0^{\circ}$ longitude, with the highest values near the Atlantic coast. The simulation (Fig. 3c) has produced realistic rates that reflect a westward shift into the second week, although the modeled maximum is displaced about $7^{\circ}$ eastward of the observed location. The simulated spatial distribution of second week precipitation by the single run that was initialized on 13 August (12 UTC), which appears as Fig. 3e, shows excellent agreement with the observed distribution, although the Atlantic coast maximum should have extended to higher latitudes. The ENS 2-week mean distribution (Fig. 3f) shows a larger area of rates exceeding $10 \mathrm{~mm}^{-1} \mathrm{y}^{-1}$ than can be interpreted from rain gauge measurements (Fig. $3 \mathrm{~g}$ ) and the simulated precipitation is conspicuously deficient along the Atlantic coast.

\section{Vorticity at $700 \mathrm{mb}$}

DFT showed how AWD are conveniently tracked on time-longitude cross sections of vorticity due to the zonal gradient of the meridional wind at 700 $\mathrm{mb}(\zeta=\Delta \mathrm{v} / \Delta \mathrm{x})$. The time-longitude cross section for ENS $\xi$, based on 3-hr resolution, is shown in Fig. 4a and can be compared to the same diagnostic for EC in Fig. $4 \mathrm{~b}$ (based on 12-hr resolution). The ENS AWD1 appears as a diagonal ribbon of maximum $\zeta$ that begins on 8 August near $15^{\circ} \mathrm{E}$ and can be traced to about $25^{\circ} \mathrm{W}$ on 15 August, implying a speed of about $/ \mathrm{ms}^{-1}$. The 
modeled AWD1 follows the same path as the EC analyzed AWD1, until it moves out over the Atlantic where the EC analysis is given fewer observations. Elsewhere on these charts, there are both agreements and disagreements between ENS and EC regarding other $\xi$ maxima. The RM results show better time continuity and therefore give smoother patterns. Fig. 4c shows the time-longitude distribution of simulated ENS precipitation. The diagonal progression of precipita'ion maxima across the chart indicates westward propagation of areas of active moist convection. Comparison with Fig. 4a shows that the eastern portion of one rainshield was situated within the quasi-stationary AWD1 $\zeta$ maximum during 8-9 August, but after AWD1 began to advance westward, the eastern edge was repositioned some $5^{\circ}$ longitude downstream of the $\zeta$ maximum. The next diagonal band of precipitation (passing through $5^{\circ} \mathrm{E}$ on 13 August) appears to move through negative vorticity and eventually reach the eastern edge of the AWD1 trough by 14 August. Reference to Fig. 1 fails to identify any single propagating synoptic feature that explains this rain band, except that other studies have found that the region immediately east of an AWD trough is often favored for precipitation because of enhanced moisture convergence within southeasterly circulation (Druyan et al., 1996).

The congruence of the simulated $\zeta$ spatial pattern with the corresponding EC $\zeta$ distribution is a measure of forecast skill that is sensitive to the handling of AWD, although EC analysis data represent an imperfect validation standard. Fig. 4c shows the time trend of the rms differences between ENS. and EC spatial distributions of $\zeta$ at $12 \mathrm{hr}$ intervals over the part of the domain that is relevant to $\operatorname{AWD}\left(5-25^{\circ} \mathrm{N}, 15^{\circ} \mathrm{E}-25^{\circ} \mathrm{W}\right)$. Rms $\zeta$ errors of persistence, also shown in Fig. 4c, are based on using the initial EC analysis as the forecast at 
each subsequent time step. The rms $\zeta$ error of persistence is already large after $12 \mathrm{hr}$ and it reaches $5 \times 10^{-6} \mathrm{~s}^{-1}$ by the end of the first day. The rms $\zeta$ error for ENS, however, increases much more gradually during the first $108 \mathrm{hr}$ (4.5 days). It stabilizes at about $3.5 \times 10^{-6} \mathrm{~s}^{-1}$ soon thereafter and it increases only slightly during the second week. The rms $\xi$ errors of the simulation ensemble are lower than persistence errors for the entire two weeks (except for the validation at $168 \mathrm{hr}$ ). These results imply that the simulations of 700 $\mathrm{mb}$ circulation are quite skillful during the first 3-4 days while they retain some skill for indefinite durations.

\section{Divergence}

Divergence is the mechanism that links synoptic circulations with broad-scale precipitation areas. The AWD composite constructed by Reed et al. (1977) included $850 \mathrm{mb}$ convergence west of the trough and $200 \mathrm{mb}$ divergence southwest of the apex, with maximum precipitation rates approximately where these centers overlap. The combination of lower tropospheric convergence and upper tropospheric divergence creates rising motions conducive to precipitation. Ideally, the AWD is sandwiched between anticyclonic ridges and descending branches associated with divergence below and convergence aloft, so that the complete circulation describes closed cells in the zonal plane. This conceptual structure is reflected in the modeled circulation on August 11 when the AWD1 $700 \mathrm{mb}$ trough was along $7.5^{\circ} \mathrm{E}$. Fig. 5a shows very strong $200 \mathrm{mb}$ divergence centered on $0^{\circ}$ and bracketed by convergence zones at $12.5^{\circ} \mathrm{W}$ and $17.5^{\circ} \mathrm{E}$. The rising branch of the AWD1 circulation in the zonal plane is further indicated in Fig. $5 \mathrm{~b}$ by $850 \mathrm{mb}$ convergence centered on 
$0^{\circ}$, with divergence to the west $\left(10^{\circ} \mathrm{N}, 12.5^{\circ} \mathrm{W}\right)$ and to the east $\left(13^{\circ} \mathrm{N}, 15^{\circ} \mathrm{E}\right)$. Substantial precipitation, observed and modeled, is apparent within a $10^{\circ}$ band under the rising node (Fig. 11), but a second area of precipitation at $10^{\circ} \mathrm{E}$ cannot be explained by the AWD circulation.

In this example, the divergence centers at $200 \mathrm{mb}$ are much broader than at $850 \mathrm{mb}$, especially in the meridional direction. Horizontal displacements between the divergence maxima and corresponding minima at the two vertical levels imply vertical tilts of the rising and descending branches, such as have been previously discussed in the literature (Reed et al., 1988; Druyan et al., 1997).

One manifestation of the subsequent weakening of AWD1 is that the 200 mb divergence maximum all but vanished by August 12 (not shown). A new strong maximum reappears near the Atlantic coast on August 14 (not shown), corresponding to increases in observed precipitation there (Fig. 1x), which were not simulated (Fig. 1v). The major line of moist convective activity on that date was further east near $5-10^{\circ} \mathrm{W}$, but only some of that activity overlaps the uplift implied by divergence distributions.

Fig. 6 shows that a swath of ENS $850 \mathrm{mb}$ convergence propagated in tandem with AWD1, coinciding with the simulated precipitation (Fig. 4c) that preceeded AWD1 (see Fig. 4a) across West Africa. The corresponding timelongitude distribution of $850 \mathrm{mb}$ divergence based on EC analyzed winds (not shown) does not show this swath, presumably because of its coarser spacetime resolution. 
There is no consistent convergence pattern in Fig. 6 corresponding to the next swath of propagating precipitation (Fig. 4c), just as there was no vorticity maximum. Spatial distributions of $850 \mathrm{mb}$ divergence show a strong north to south directed gradient near $13^{\circ} \mathrm{N}$ over the Central Sahel on 13-15 August, but the simulated precipitation is mostly within $(850 \mathrm{mb})$ divergence. Plumes of uplift are often tilted (Reed et al., 1988; Druyan et al., 1997), and strong convergence was indeed present at 700-500 mb over these precipitation regions, implying that moist convection was probably initiated in the midtroposphere.

\section{Periodicity}

Spectral analysis is a more objective method for determining the periodicity of model simulated AWD. However, much longer time series than those studied here are required to analyze spectral peaks relevant to AWD, namely those with 3-9 day periods. Alternatively, wavelet analysis (Torrence and Compo, 1998) offers the opportunity to detect the temporal variation of spectral properties, even for short records. Diedhiou et al. (1999) applied wavelet analysis to the mean daily $700 \mathrm{mb}$ meridional wind over West Africa from NCEP and ECMWF data sets for June-September 1988.

Fig. 7 shows the wavelet results for the RM $700 \mathrm{mb}$ meridional wind (v7) component at five locations over the model domain. Since the time series are relatively short compared with the dominant periodicities, spectral resolution is somewhat coarse. Within the range of interest, spectral amplitudes are computed for periods of $1.9,2.8,3.9,5.5$ and 7.8 days. The non-shaded areas in 
Fig. 7 indicate where there is greater than $95 \%$ probability that departures of the wavelet amplitude from a comparable red noise spectrum are statistically significant using a $\chi^{2}$ distribution. The most frequent spectral maximum that was analyzed from this simulation was at 3.9 days (at three of the five grid points). This is consistent with many studies that found spectral peaks for AWD at periods between 3-5 days (Burpee, 1972; Diedhiou et al., 1999). Fig. 7 shows that at $15^{\circ} \mathrm{N}, 0^{\circ}$ and $15^{\circ} \mathrm{N}, 10^{\circ} \mathrm{W}, 5-8$ - day periods dominate. The wavelet analysis for $15^{\circ} \mathrm{N}, 10^{\circ} \mathrm{E}$ also shows that the wave activity in the east was most prominent during the first week, while at $0^{\circ}$ and $10^{\circ} \mathrm{W}$, periodic variability of $\mathrm{v} 7$ was stronger into the second week.

\section{Constant LBC}

DFT had reported on a low sensitivity of RM simulations to constant lateral boundary conditions (LBC). This was a rather surprising result which was either a peculiarity of West African weather or those particular simulations. In order to address this matter, we repeated the 8-15 August simulation, but imposed constant LBC in two runs from arbitrarily varied initial conditions. (Random perturbations of $-1.5 \mathrm{mb}<\Delta \mathrm{P}<+1.5 \mathrm{mb}$ were applied to the initial surface pressure field in order to create the second set of initial conditions.) Both constant LBC simulations severely damped amplitudes of simulated AWD and both caused a degradation of the $\zeta$ simulation, resulting in 25-30\% higher rms $\xi$ errors compared with ENS after the fifth day. Moreover, these simulations underestimated rainfall over the Central Sahel, and were accordingly less realistic than ENS. Damped AWD amplitudes may in part be explained by the fact that constant LBC do not allow periodic variations to 
enter via the lateral boundaries. Other explanations were sought by evaluating the following experiments.

Since the experiments described by DFT did not include the preliminary spin-up of moisture or dynamic initialization, we tested their impact combined with constant $L B C$ in two additional experiments. In one constant LBC run, all latent heat releases were eliminated in order to evaluate the role. of latent heat feedbacks on the circulation. This simulation achieved somewhat more realistic mid-tropospheric circulation patterns than the two fully initialized constant LBC experiments, decreasing the rms $\zeta$ error by about $8 \%$. The second constant LBC simulation which used spin-up moisture but not dynamic initialization also improved the subsequent evolution of the mid-tropospheric circulation (15\% decrease in $\mathrm{rms} \xi$ error). These results imply that the initialization process increases the RM sensitivity to the quality of LBC, but the effect cannot be demonstrated with objective statistical significance since conclusions are based on single simulations.

\section{Conclusions}

RM simulations of West Africa summertime weather and climate at $50 \mathrm{~km}$ horizontal resolution offer unique opportunities to study the relationships between circulation and precipitation. The current simulations represent an improvement over previous RM results discussed in DFT. Better temporal and spatial distributions of simulated precipitation were achieved by introducing an initialization procedure that makes observed initial

3 conditions more compatible with model physics. The procedure incorporates 
a 24-hr spin-up moisture field and an iterative dynamic forward-backward integration of the equations of motion in order to eliminate high frequency gravity waves.

RM simulations forced by synchronously updated ECMWF data as lateral boundary conditions produce a realistic evolution of the mid-tropospheric circulation. Vorticity errors of a 4-run simulation ensemble leveled off after about three days and thereafter hovered at values that were at least $30 \%$ lower than persistence errors.

The simulated distribution of taily precipitation has been validated over a 2-week period against rain gaug، data and satellite infrared cloud imagery over West Africa. The correspondence between modeled precipitation distributions and observational $€ \cdot v i d e n c e$ is best within the first three days after the initial conditions. Simulated precipitation rates became unrealistically lower after about five days and into the second week, perhaps related to a concomitant weaker circulation. Dramatic improvement in the time-space distribution of model precipitation for the last 9 days was accomplished by reinitializing the model with ECMWF data on day 5 . It is not clear whether this reflects the range of model skill or the range of ECMWF analysis quality.

A prominent AWD traversed the entire span of West Africa during the first five days of the study and the RM simulated its circulation and an associated region of active moist convection that advanced westward ahead of the wave trough. The simulation showed that the AWD was most organized on day 3 when the zonal cellular structur: was clearly discernable. The main area of 
associated precipitation was situated under the rising branch of the cells capped by a broad region of upper tropospheric divergence and bracketed by descending branches about $15^{\circ}$ to the east and west. ECMWF analyses, on the other hand, provided an imperfect picture of these divergence distributions owing to their coarse time-space resolution. Several of the other precipitation areas, both modeled and observed, were not associated with AWD related uplift or lower tropospheric confluence zones.

Wavelet analysis of the $700 \mathrm{mb}$ meridional wind (v7) from the four simulations detected $A W D$ with characteristic 3.9 day periodicity, although slightly longer periods dominated at $15^{\circ} \mathrm{N}, 0^{\circ}-10^{\circ} \mathrm{W}$. Periodic variability of v7 was stronger in the first week at $10^{\circ} \mathrm{E}$ and lasted progressively longer in the downstream westward direction, spanning almost the entire two week length of the simulations at $10^{\circ} \mathrm{W}$.

Two simulations forced by constant LBC showed considerable degradation of the circulation. Additional experiments implied that this negative impact of LBC could be related to the initialization procedure. Dynamic initialization may deprive the model of valuable information which can be restored only when the LBC are updated with synchronous observational data. Moreover, in a single simulation without latent heat releases, constant LBC were also not quite as damaging to the model mid-troposhperic circulation, implying that the model may be more sensitive to constant LBC when there are strong feedbacks from high precipitation rates. Accordingly, initializing with a more compatible initial moisture field apparently increases the importance of latent heat feedbacks on the simulated circulation. These results may have implications for daily or seasonal predictions since such simulations cannot 
benefit from $L B C$ derived from observations. However, since these inferences have been drawn from a limited number of simulations of a particular case study, they should be contemplated with caution. Finally, additional testing is needed to determine the sensitivity of model simulations to LBC supplied by GCMs, which do provide time dependant information, although less realistic than data from updated observational analyses.

This study has demonstrated the utility of using high resolution simulations for diagnostic investigations of African wave disturbances. Many more RM simulations need to be analyzed to generalize conclusions and to more completely document model performance. Still, these RM results are encouraging. These are necessary preliminaries to the application of regional models for weather and seasonal climate prediction over West Africa. Future work will accordingly evaluate monthly and seasonal mean fields forced by both analyses and GCMs.

Acknowledgments. This research was funded by the National Science Foundation under grant ATM 97-25142, by the NASA Climate and Earth Observing System Programs, and by the National Research Council of the National Academy of Sciences.

\section{REFERENCES}

Bounoua, L., 1992: Land Surface Processes and Climate Modeling. PhD Dissertation, 196 pp., Dept. of Meteorology, The Florida State University. 
Burpee, R., 1972: The origin and structure of easterly waves in the lower troposphere of North Africa. J. Atmos. Sci., 29, 77-90.

Dastoor, A., and T.N. Krishnamurti, 1991: Landfall and structure of a tropical cyclone : Sensitivity of the model predictions to soil moisture parameterization. Bound. Layer Meteor., 55, 345-380.

Deardoff, J., 1978: Efficient prediction of ground surface temperature and moisture with inclusion of a lay ar of vegetation. JGR, 83, 1889-1903.

Diedhiou, A., S. Janicot, A. Viltard, P. le Felice and H. Laurent, 1999: Easterly wave regimes and associated ccnvection over West Africa and tropical Atlantic: results from NCEP/NCAR and ECMWF reanalyses. Climate Dynamics, 15, 795-822.

Druyan, L., P. Lonergan and M. Saloum, 1996: African wave disturbances and precipitation at Niamey during July-August 1987-1988. Climate Research, 7, 71-83.

Druyan, L., P. Lonergan and J. Cohen, 1997: Case studies of African wave disturbances in gridded analyses, Mon.Weather Rev., 125, 2520-2530.

Druyan, L., M. Fulakeza and W. Thiaw, 2000: Regional model simulations of African wave disturbances. JGR, 105, 7231-7255.

Fulakeza, M., 1998: Modeling regional climate of southern central Africa, 243 pp. PhD dissertation, Dept. If Meteorology, Florida State Univ. 
Giorgi, F. and L. Mearns, 1999: Introduction to special section: Regional climate modeling revisited. J. Geophys Res., 104, 6335-6352.

Giorgi, F., M. Marinucci, and G. Bates, 1993a: Development of a secondgeneration regional climate model (RegCM2). Part I: Boundary-layer and radiative transfer processes. Mon. Wea. Rev., 121, 2794-2813.

Giorgi, F., M. Marinucci, and G. Bates, 1993b: Development of a secondgeneration regional climate model (RegCM2). Part II: Convective processes and assimilation of lateral boundary conditions. Mon. Wea. Rev., 121, 2814-2832.

Haltiner, G. J. and R. T. Williams, 1980, Numerical Prediction and Dynamic Meteorology, John Wiley and Sons, 477pp.

Jenkins, G., 1997: The 1988 and 1990 summer season simulations for West Africa using a regional climate model, J. Climate, 10, 1255-1272.

Kamara, S., 1986: The origins and types of rainfall in West Africa. Weather, 41, 48-56.

Krishnamurti, T.N., S. Low-Nam and R. Pasch, 1983: Cumulus parameterization and rainfall rates II, Mon. Weather Rev., 111, 815-828. 
Krishnamurti, T. N., A. Kumar, K. S. Yap, A. P. Dastoor, N. Davidson and J. Sheng, 1990, Performance of high resolution mesoscale tropical prediction model. Advances in Geophysics, eds. R. Dmowska and B. Saltzman, 32, 133-286.

Kumar, A., 1989: A documentation of the FSU limited area model. Rep. No. 89-4, 301 pp., Dept. of Meteorology, Florida State Universisty.

Kuo, H., 1974: Further studies of the parameterization of the influence of cumulus convection on large-scale flow. J. Atmos. Sci., 31, 1232-1240.

Peters, M., G. Tetzlaff and W. Janssen, 1989: Rainfall intensity of West African squall lines. Annales Geophysicae, 7, 227-238.

Reed, R., D. Norquist and E. Recker, 1977: The structure and properties of African wave disturbances as observed during Phase III of GATE. Mon. Weather Rev., 105, 317-333.

Reed, R., E. Klinker and A. Holingsworth, 1988: The structure and characteristics of African easterly wave disturbances as determined from the ECMWF operational analysis/forecast system. Meteor. Atmos. Phys., 38, 22-33.

Semazzi, F., N-H. Lin, Y-L. Lin and F. Giorgi, 1993: A nested model study of the Sahelian climate response to SST anomalies. Geophys. Res. Let., 20, 2897-2900. 
Sugi, M, 1986, Dynamic normal mode initialization. J. Met. Soc. of Japan, 64, 623-636.

Sun, L., F. Semazzi, F. Giorgi and L. Ogallo, 1999a: Application of the NCAR regional climate model to eastern Africa. 1. Simulation of the short rains of 1988, JGR 104, 6529-6548.

Sun, L., F. Semazzi, F. Giorgi and L. Ogallo, 1999b: Application of the NCAR regional climate model to eastern Africa. 2. Simulation of interannual variability of short rains, JGR 104, 65429-6562.

Torrence, C. and G. Compo, 1998: A practical guide to wavelet analysis. Bull. AMS, 79, 61-78.

Xue, Y. and J. Shukla, 1993: The influence of land surface properties on Sahel climate. Part I: Desertification, J. Climate, 6, 2232-2245. 


\section{Figures}

1. a)-z") Circulation at $700 \mathrm{mb}, 24-\mathrm{h}$ precipitation totals and cloud imagery for each day, 9-15 August 1988.

Left: ECMWF 00 UTC and 12 UTC resultant winds. Dashed lines indicate major troughs.

Second from left: ENS resultant winds of 3- hourly fields. ENS precipitation contours are given at $5 \mathrm{~mm}$ intervals.

Second from right: ISCCP B3 infrared imagery at 15 UTC.

Right: Spatial distribution of observed precipitation $(\mathrm{mm})$ based on rain gauge measurements (whose locations are indicated by dots).

2. Validation of area-averaged daily precipitation totals.

a) "Obs" refers to the mean of three rain gauges within the designated area. "RM" refers to ENS results representing the mean of the four grid points bordering the designated area. "RM2" is like "RM", but for the single simulation initialized at 12 UTC on 13 August 1988.

b) "Obs" refers to the mean of six rain gauges within the designated area. "RM" refers to ENS results representing the mean of the twelve grid points bordering the designated area. "RM2" is like "RM", but for the single simulation initialized at 12 UTC on 13 August 1988.

c) "Obs" refers to the mean of 18-19 rain gauges within the designated area. "RM" refers to ENS results representing the mean of the 162 grid points bordering the designated area. "RM2" is like "RM", but for the single simulation initialized at 12 UTC on 13 August 1988. 
3. Spatial distributions of time averaged precipitation rates $\left(\mathrm{mm}\right.$ day $\left.^{-1}\right)$. Top row: ENS results for a) 9-15 August 1988, c) 16-22 August 1988 and f) 9-22 August 1988 .

Middle row: observed distributions based on rain gauge measurements (station locations indicated) for b) 9-15 August 1988, d) 16-22 August 1988 and g) 9-22 August 1988.

e) RM results for 16-22 August 1988 based on a single simulation initialized on 13 August, 12 UTC.

4. Time-longitude distribution of $700 \mathrm{mb}$ vorticity due to the zonal gradient of the meridional wind $(\xi \equiv \Delta v / \Delta x)$ averaged over $12-20^{\circ} \mathrm{N}$. a) RM ENS at 3-hr intervals, b) ECMWF at 12 -hr intervals. $\xi=0$ is bold and $\xi$ maxima are stippled.

c) Time-longitude distribution of ENS precipitation rate averaged over 10-20 ${ }^{\circ} \mathrm{N}$. Contours are $2,4,6,8,10 \mathrm{~mm}$ day $^{-1}$.

d) Root-mean-square of ENS errors in $\xi$ at $12 \mathrm{hr}$ intervals, validated against ECMWF analyses within the area $5-25^{\circ} \mathrm{N}, 25^{\circ} \mathrm{W}-15^{\circ} \mathrm{E}$. Persistence errors represent the $\mathrm{rms} \xi$ differences between the ECMWF analysis at 12 UTC 8 August 1988 and subsequent ECMWF $\xi$ fields.

Units for $\xi: 10^{-6} \mathrm{~s}^{-1}$. Labels along vertical axis in a.- c. indicate 12 UTC on the designated day.

5. Horizontal distributions of divergence computed for ENS resultant winds at a) $200 \mathrm{mb}$ and b) $850 \mathrm{mb}$ for 11 August 1988. Units: $10^{-6} \mathrm{~s}^{-1}$. 
6. Time-longitude distribution of ENS $850 \mathrm{mb}$ divergence $\left(10^{-6} \mathrm{~s}^{-1}\right)$ averaged over $10-20^{\circ} \mathrm{N}$. Units: $10^{-6} \mathrm{~s}^{-1}$.

7. Wavelet analysis of $700 \mathrm{mb}$ meridional wind time series at five locations (coordinates given). Spectral amplitudes $\left(\mathrm{m} \mathrm{s}^{-1}\right)$ have been averaged over the four simulations of ENS and are mapped against periodicity (vertical axis) and elapsed time (horizontal axis). Non-shaded areas indicate $>95 \%$ probability that departures of the wavelet amplitude from a comparable red noise spectrum are statistically significant using a $\chi^{2}$ distribution. 

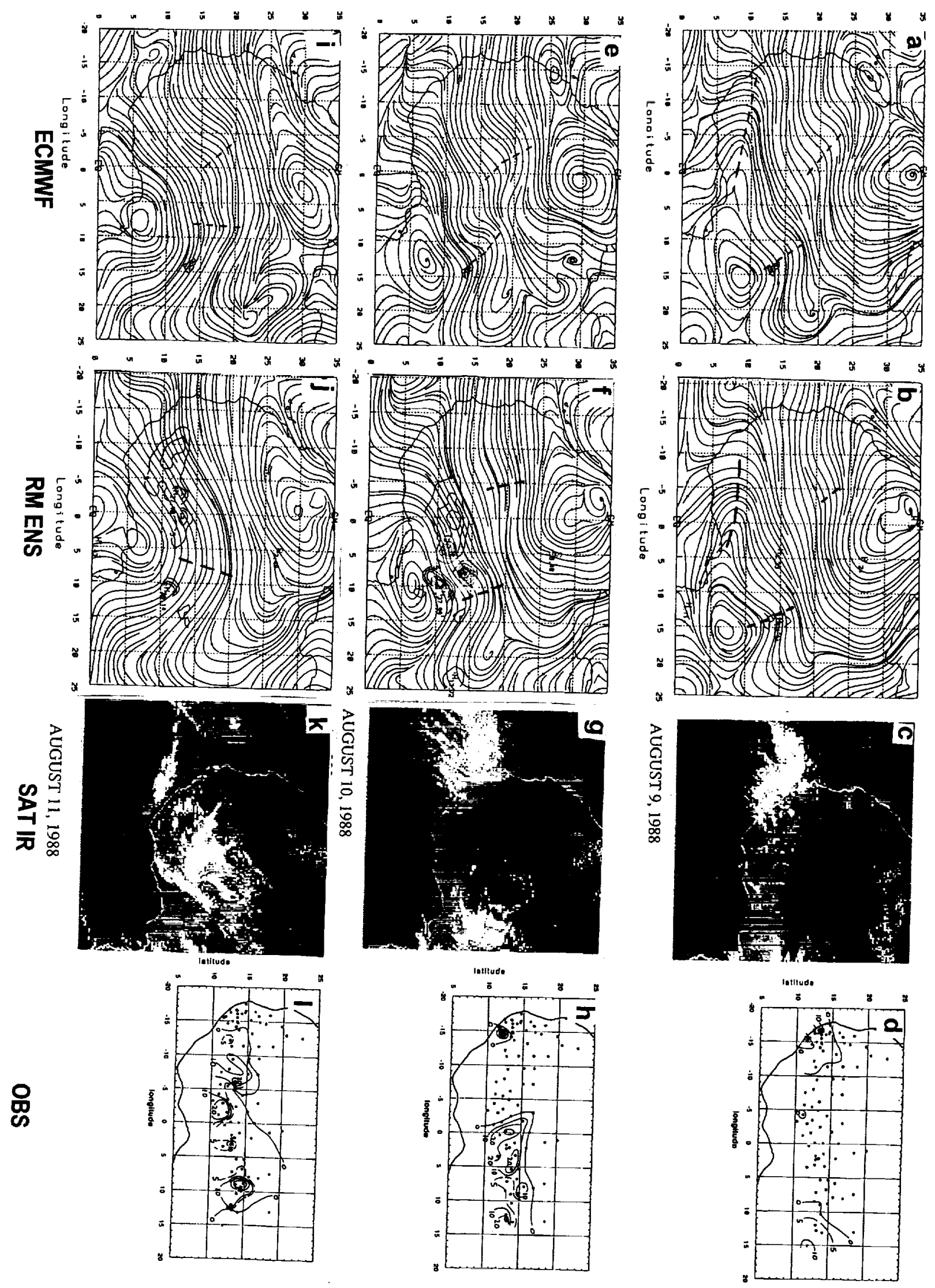

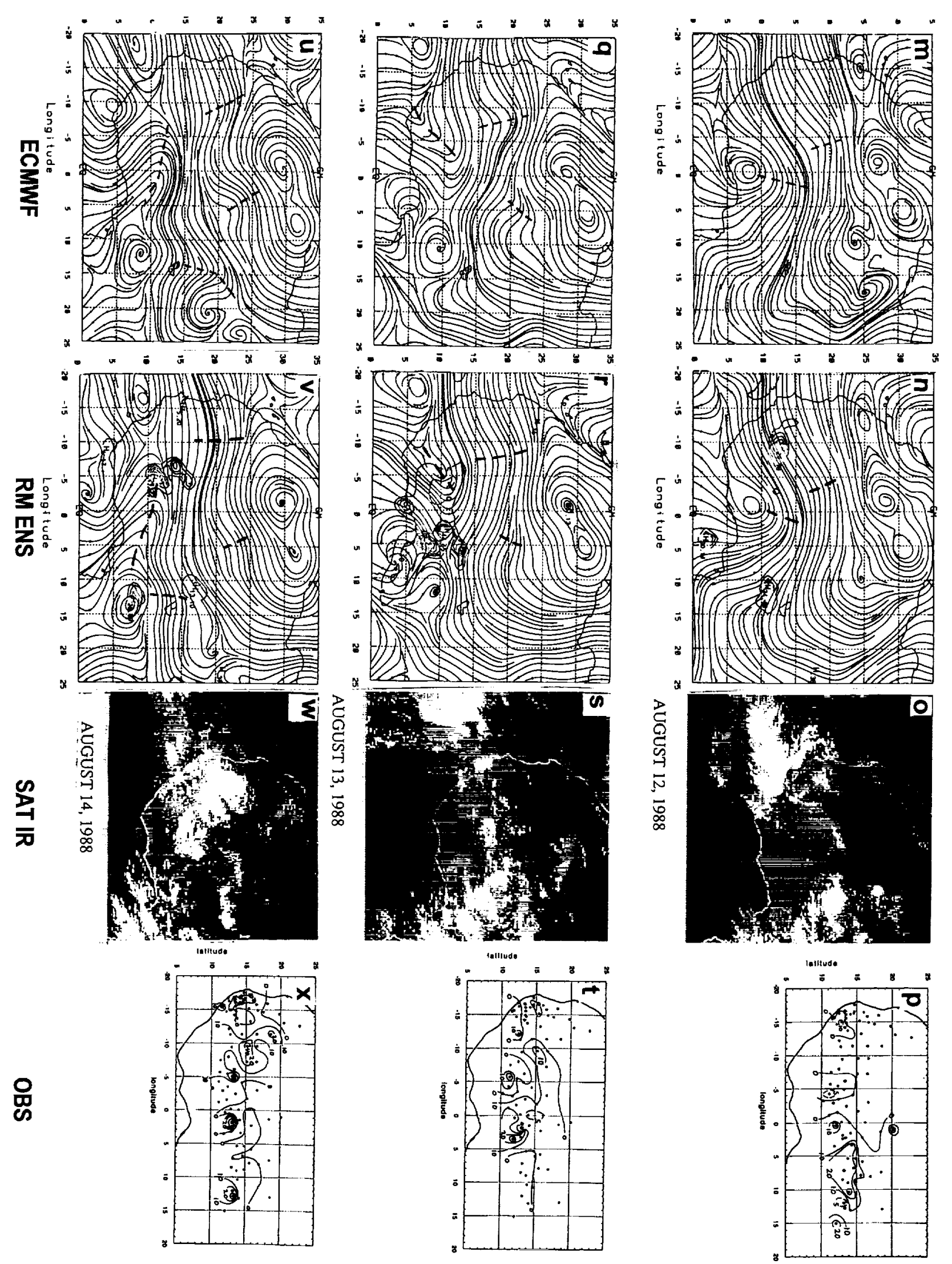


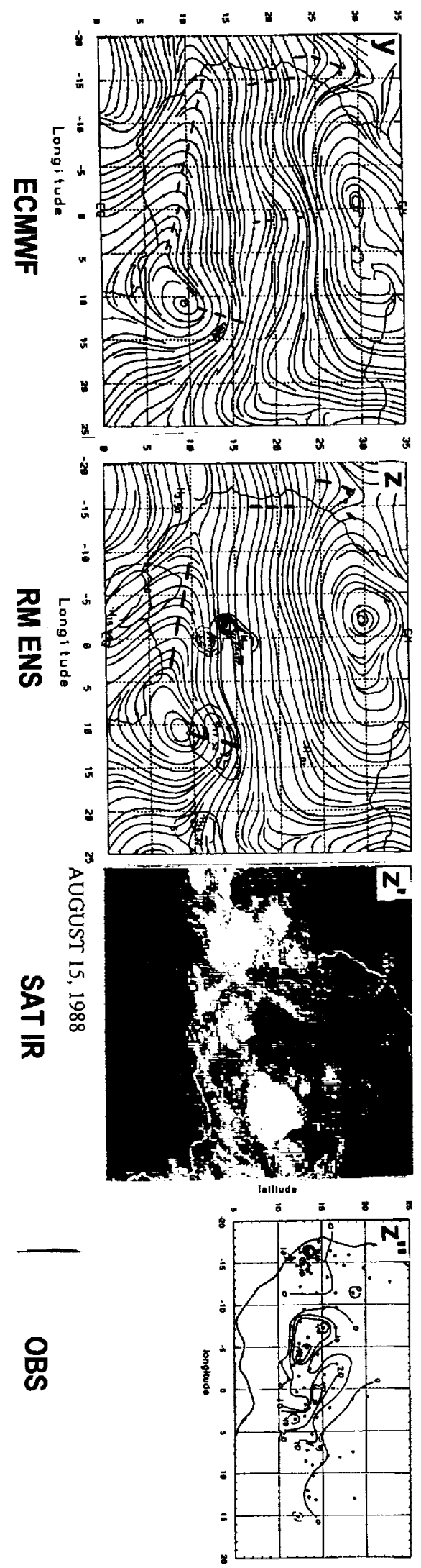

$\rightarrow$ 


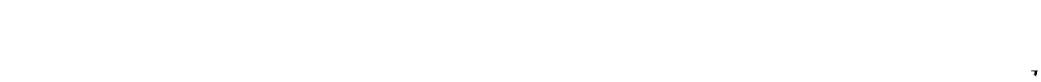

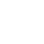



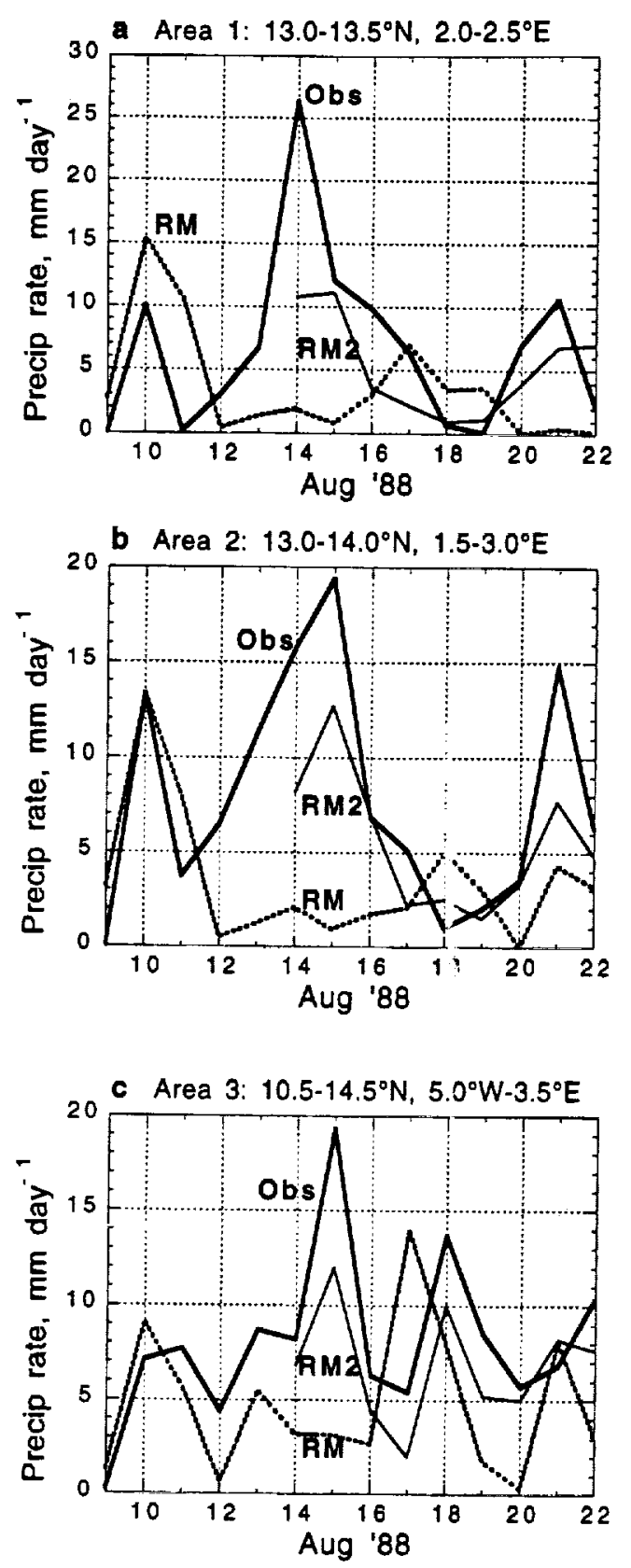


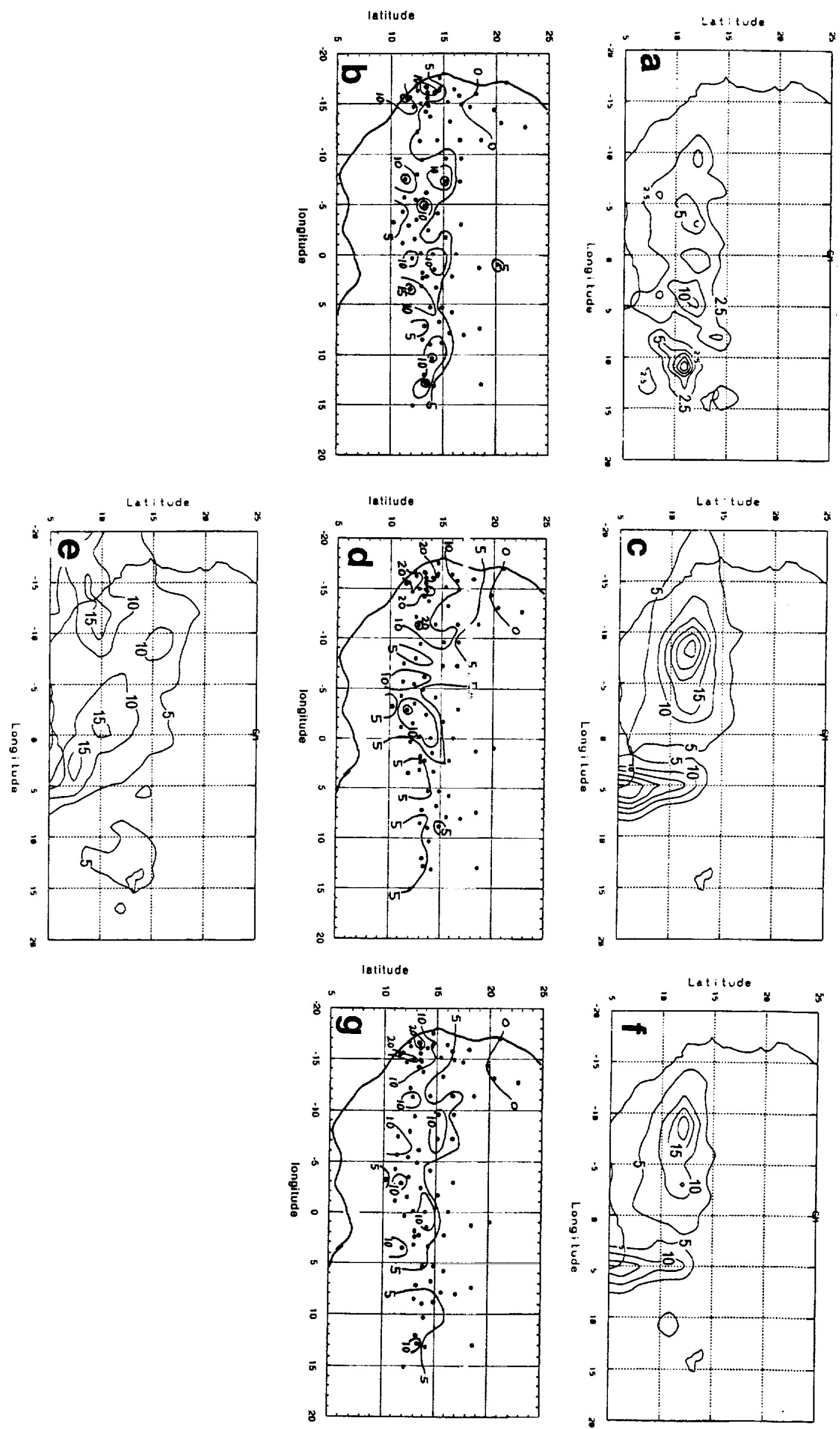

$w$ 


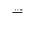

$=$ 

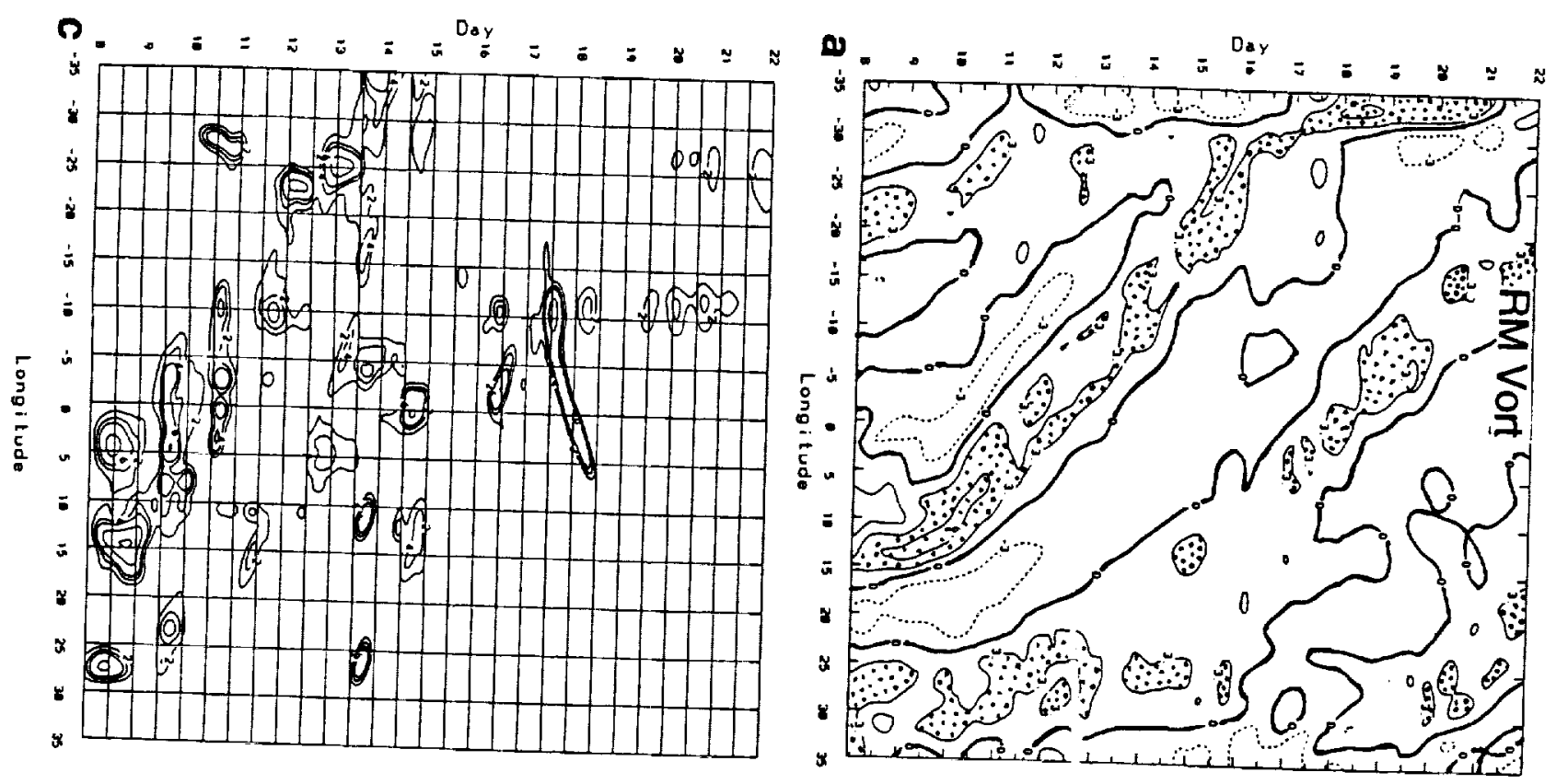

\section{e}
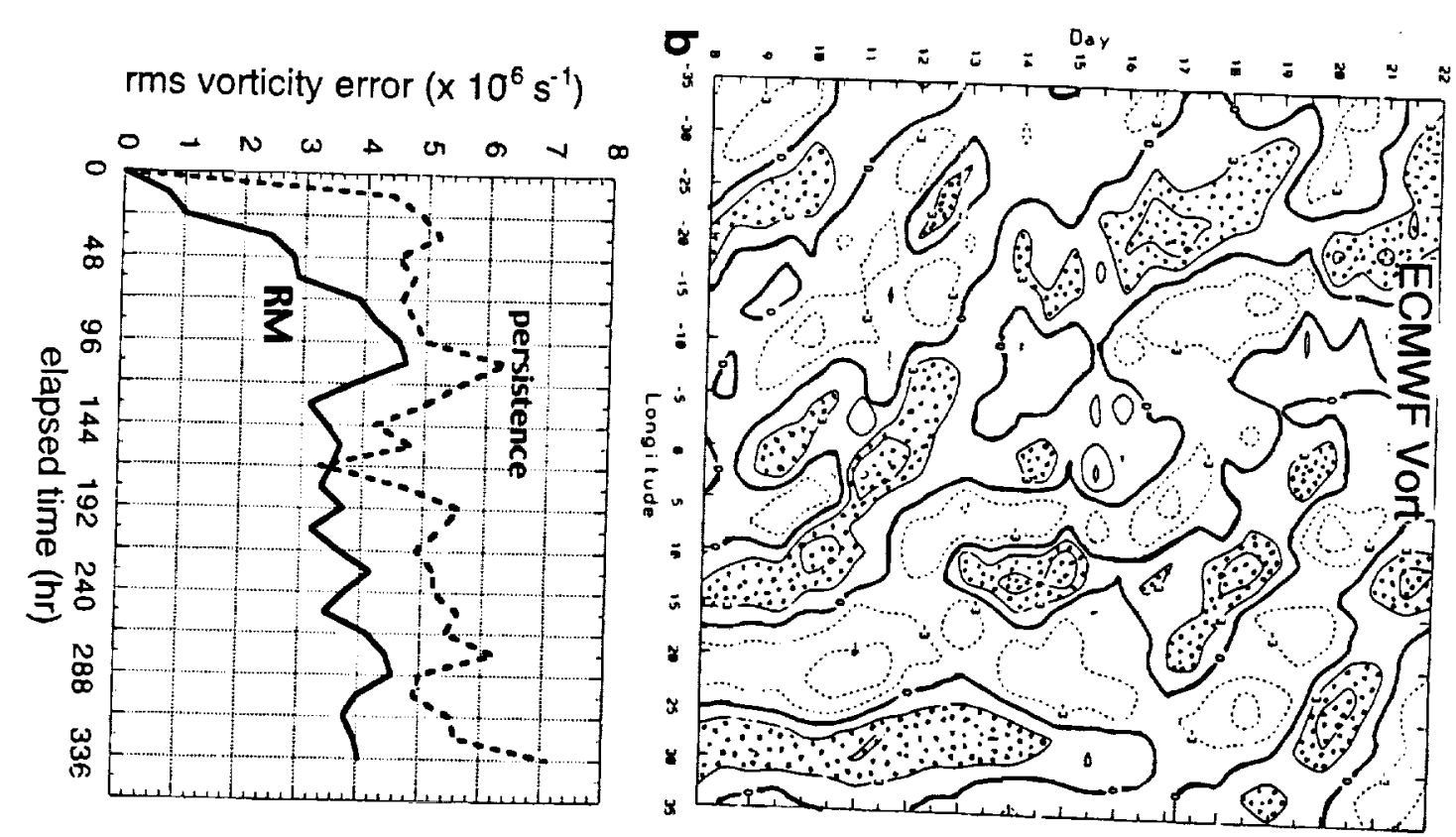



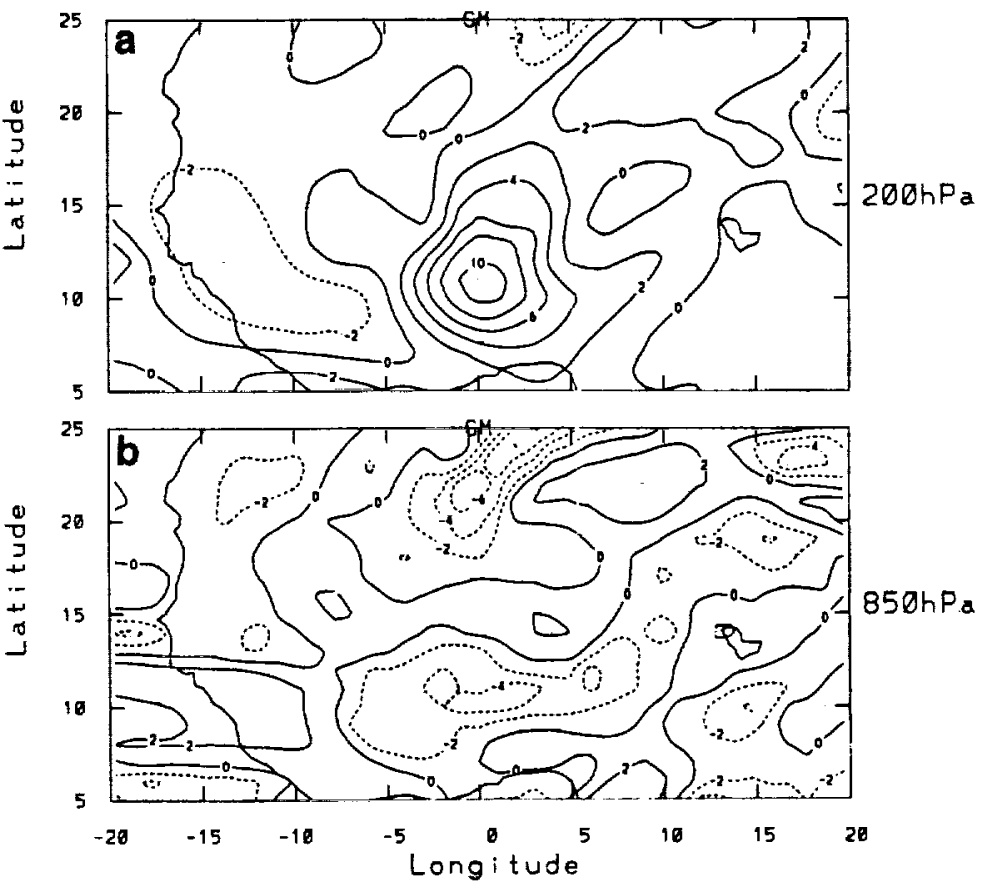




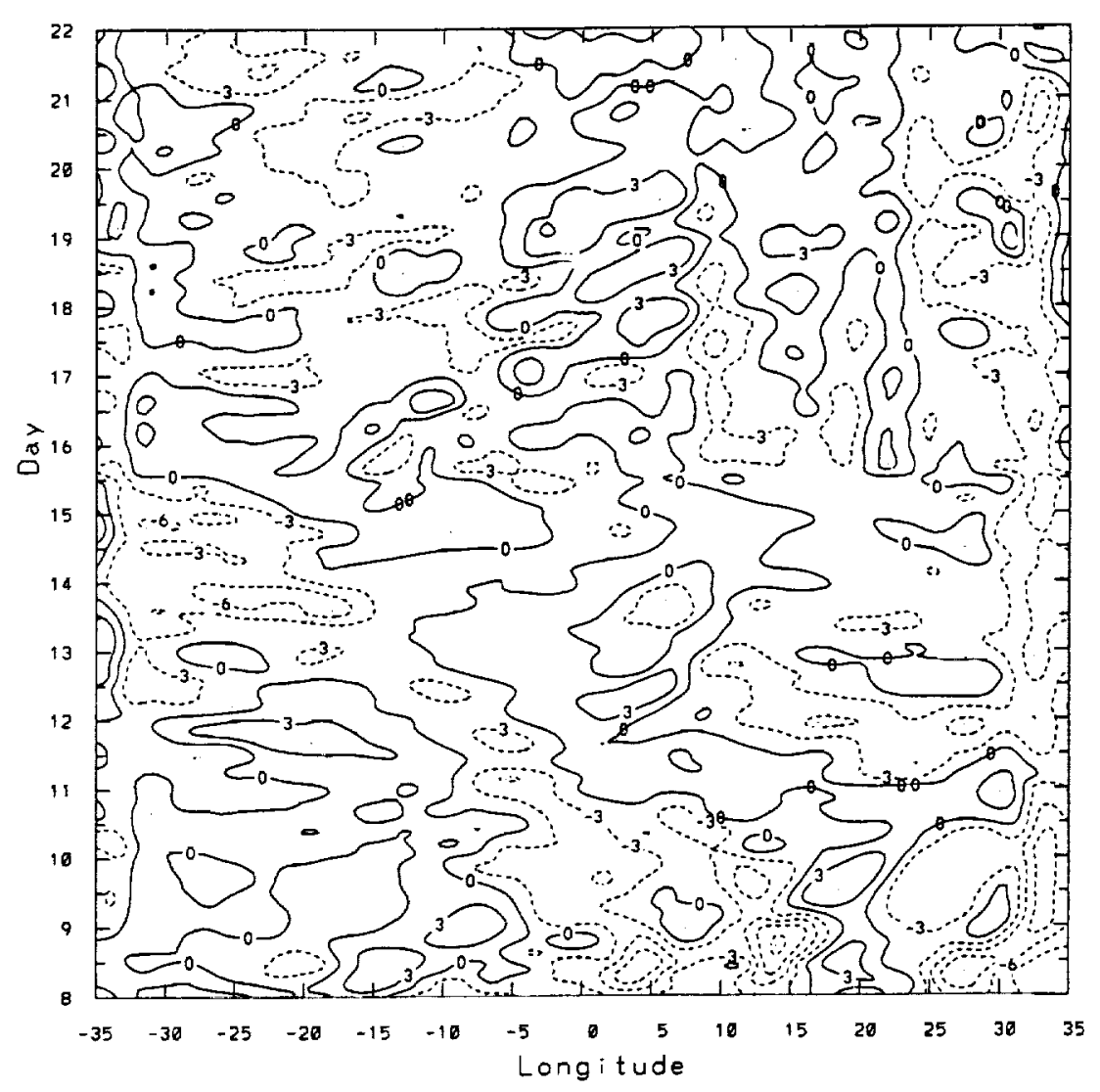




